\title{
Determination of ground reaction force peaks from human footprint depths
}

\author{
Gustavo Balbinot ${ }^{1 *}$, Alberito R. de Carvalho ${ }^{2}$, Clarissa Pedrini Schuch ${ }^{2}$, Renata Luisa Bona ${ }^{2}$, \\ C. Gabriel Fábrica ${ }^{3}$, Leonardo Alexandre Peyré Tartaruga ${ }^{2}$ \\ ${ }^{I}$ Department of neuroscience, Federal University of Rio Grande do Norte (UFRN), Brain Institute, Natal, RN, Brazil \\ ${ }^{2}$ School of physical education, Federal University of Rio Grande do Sul (UFRGS), Porto Alegre, RS, Brazil \\ ${ }^{3}$ Department of biophysics, Facultad de Medicine, Universidad de la república, Montevideo, Uruguay \\ *Corresponding author E-mail: gustavo.balbinot@hotmail.com
}

Copyright $\odot 2014$ Gustavo Balbinot et al. This is an open access article distributed under the Creative Commons Attribution License, which permits unrestricted use, distribution, and reproduction in any medium, provided the original work is properly cited.

\begin{abstract}
The aim of the present study was to estimate ground reaction force (GRF) by means of a linear regression equation with input data from footprints. It can be used to provide further information on locomotion of extinct mammals and/or early humans, thus providing important knowledge about human bipedal locomotion evolution. Fossilized footprints contain information about gait dynamics, but their interpretation is difficult, as they are a combined result of foot anatomy, gait dynamics, and substrate properties. Several approaches are used for modeling and estimating data in biomechanics, simple modeling is useful when trying to understand complex events. Force measurements were performed using a force platform; at the same time a footprint was registered on a clay surface. From the measurements of length, width and depth of the footprint it was possible to estimate body height (BH), body mass (BM) and vertical GRF peaks during human walking. The main findings of the present study were two linear regression equations for estimation of GRF peaks from footprint depths $\left(\mathrm{R}^{2}=0.81, \mathrm{p}<0.001 ; \mathrm{R}^{2}=0.56, \mathrm{p}<0.001\right)$. This study accomplishes a first step to a fully understanding of how to estimate GRF from footprint data, and have further application to locomotion evaluations from fossilized footprints.
\end{abstract}

Keywords: footprint, ground reaction force, locomotion, linear regression, gait.

\section{Introduction}

Human ancestral footprints such as the Laetoli footprints (Australopithecus afarensis), an early hominid whose fossils were found in a near sediment layer, are usual and largely studied [1, 2]. The entire footprint trail is almost $27 \mathrm{~m}(88 \mathrm{ft})$ long and includes impressions of about 70 early human footprints. Those footprints have important and unique information and are very challenging to study, due to the complex interaction between weather and substrate. Several approaches are used for modeling and estimating data in biomechanics, simple modeling is useful when trying to understand complex events [3]. Data inputs such as stride length, duty factor (fraction of stride time at which only one foot is in contact with the ground) and GRF patterns are used in order to understand locomotion [4]. Different methods are used to study extinct species and to understand locomotion patterns, or even specific interplay between species, for example, from data collected from bones [5] and utilizing several mathematical approaches [6].

An important source of pre historic information from extinct animals is their traces over the ground soil. These animals or hominids had left behind precious information lying on their resting fossilized footprints [7]. By studying footprints, paleontologists can learn about dinosaurs size [8] and whether it was an herbivore or a predator [9]; from foot shape and/or the presence or absence of claws. Footprints may also give clues about the type of environment and climate where the extant animals lived [6]. In the same way, through human footprints it is possible to understand the process of evolution (e.g. reduced energy costs of locomotion in hominids) [10], [2]. Currently, criminal studies use footprint analysis (length and width of the foot) as evidence for estimation of body size (e.g. stature, body weight). Several studies support the relationship between gender, BM and BH, and the footprint pattern [11], [12], [13], [14], [15]. 
However, most of the studies analyses pre-historic footprints on 2D features (length and width) [16]. But, the footprint contains several 3D information such as volume and depth associated with surface deformation. The interaction between ground surface and foot creates a plastic deformation. This plastic deformation depends on many factors, for example, substrate mechanical properties (sediment composition, humidity and how the load was applied) [16], [17]. And the characteristics of this deformation depend on the force exerted by the human or animal during the support phase.

The hypothesis of this study was that by means of a linear regression equation approach physical characteristics of individuals can be predicted, as well as their GRF peaks, on a 3D footprints based approach (length, width and depth). From footprints performed over a clay soil, we experimentally performed measurements of length, width and depth, and associated this outcomes with GRFs data; by this means we sought to establish a mathematical relation between these variables and to formulate a linear regression equation, which could be utilized to estimate mechanical work and energy expenditure parameters from fossilized footprints and lead to a better knowledge on human evolution [18], [19].

\section{Materials and methods}

\subsection{Participants}

This study is characterized as a cross-sectional quantitative comparison. The sample was composed of ten individuals with average $\mathrm{BM}$ and $\mathrm{BH}$ of $67.21 \pm 11.21 \mathrm{~kg}$ and $1.73 \pm 0.08 \mathrm{~m}$, respectively. Volunteers were healthy, without notable asymmetries on lower limbs alignment and without history of orthopedic trauma. The experiments were carried out at the Laboratory for Biomechanics of the Federal University of Rio Grande do Sul (Brazil).

\subsection{Data acquisition and processing}

A rectangular wood rack $(44.0 \times 29.5 \times 2.5 \mathrm{~cm})$ was constructed for footprint pattern collection and served to limit the $\approx 5 \mathrm{~kg}$ clay content. Force plate (AMTI-OR6, Advance Mechanical Technology, Waterton, MA) and clay rack were integrated to measure the footprint depth due to GRF action (Fig. 1).

(a)

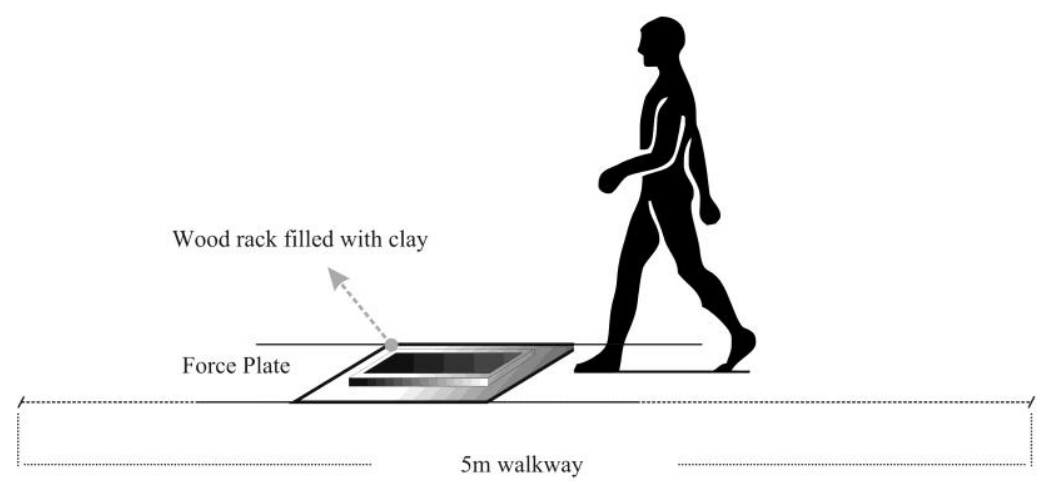

(b)

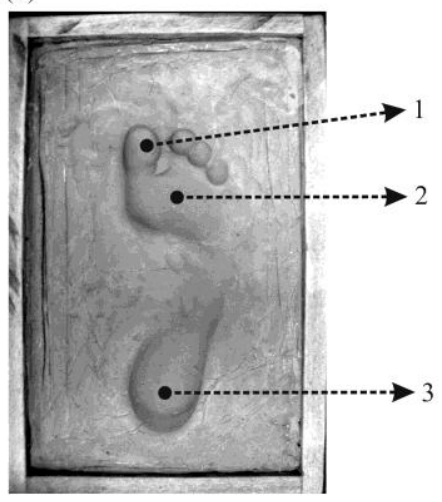

Fig. 1: (a) Force plate and wood rack filled with clay. (b) Footprint and measuring points: (1) Hallux depth: deepest point at the hallux area; (2) Metatarsal depth: deepest point at the base of the metatarsal; (3) Calcaneus depth: deepest point at the heel area.

Initially the subjects were instructed to stand still over the force plate to record BM. Afterwards; we weighted the total amount of clay together with wood rack, so we could extract the offset signal. The setup consisted of a $5 \mathrm{~m}$ long walkway where the volunteers were instructed to walk at a self-select speed (SS), above and below SS. Each subject performed 10 level walking trials over the force platform, after each walking trial a trained team of researchers measured the footprint parameters. Trials were considered valid if the whole right foot touched the wood rack+clay+force plate apparatus. After each trial, several linear measurements were executed in the footprint utilizing a caliper rule (Tresna, EC16, Guilin Guanglu Measuring Instrument, and China):

1) Foot Length (FL): distance between the most prominent points at the heel to the most prominent point of longest toe, following the direction of the longitudinal axis of the foot $(\mathrm{cm})$ [20], [21].

2) Foot Width (FW): distance in centimetres between the most prominent point at the medial head of the $1^{\circ}$ metatarsal to the most prominent point at the lateral region of $5^{\circ}$ metatarsal head $(\mathrm{cm})$;

3) Calcaneus depth $\left(\right.$ Calcaneus $\left._{\text {depth }}\right)$ : deepest point at the heel area $(\mathrm{cm})$;

4) Metatarsal depth $\left(\right.$ Metatarsal $\left._{\text {depth }}\right)$ : deepest point at the base of the metatarsal $(\mathrm{cm})$;

5) Hallux depth $\left(\right.$ Hallux $\left._{\text {depth }}\right)$ : deepest point at the hallux area $(\mathrm{cm})$. 
From footprint measurements it was possible to estimate subject's BH applying Krishan (2008a; 2008b) equation. Authors found a strong positive correlation between BH and FL and between BH and FW. In our study, the prediction of $\mathrm{BH}$ was performed using as input data $\mathrm{FW}$, as the following (Eq. 1):

$B H=5.414 \times F W+120.951$

Where $\mathrm{BH}$ is the body height $(\mathrm{cm})$ and $\mathrm{FW}$ is foot width $(\mathrm{cm})$.

For comparison reasons, BM was obtained using two equations from Krishan's studies [14, 15]:

$\mathrm{BM}$ obtained from foot length (FL) measurement applying the following equation (Eq. 2):

$B M=1.22 \times F L+37.75$

BM obtained from foot width (FW) measurement applying the following equation (Eq. 3):

$B M=2.86 \times F W+37.63$

Where BM is body mass $(\mathrm{kg}), \mathrm{FL}$ is foot length $(\mathrm{cm})$ and FW is foot width $(\mathrm{cm})$.

Equations (1, 2 and 3) described above are related to right foot measurements.

Data acquisition and analysis for GRF were performed with a sampling frequency of $1000 \mathrm{~Hz}$ coupled to a signal conditioner and A/D converter (16-bit, computer boards). For force plate data filtering a low-pass $4^{\text {th }}$ order Butterworth filter, cut-off frequency of $70 \mathrm{~Hz}$ was employed. The signals were then processed using SAD32 software (UFRGS, Porto Alegre, RS, Brazil). A MATLAB ${ }^{\mathrm{TM}} 7.1$ (Mathworks Inc, Natick, Massachusetts, USA) mathematical routine was constructed to data filtering and first and second GRF peaks extraction.

Finally, average horizontal velocities during trials were determined using a video analysis system (Digital Video for Biomechanics 5.0, UNICAMP, São Paulo, Brazil). Which consisted of a video camera (JVC GR-DVL 9800 - JVC Company of America, Wayne, New Jersey, USA), a spotlight, a 2D calibrator and a reflective marker fixed at the subject's neck. For BH measurements a stadiometer was employed (Wiso, 0cm-210cm, Santa Catarina, Brazil).

\subsection{Linear regression equations}

Calcaneus, metatarsals and hallux depth values and GRF peaks were the input data for the linear regression equations construction. The first GRF peak $\left(\mathrm{GRF}_{1}\right)$ was correlated with maximum depth for calcaneus region $\left(\mathrm{Calcaneus}_{\mathrm{depth}}\right)$ and the second GRF peak $\left(\mathrm{GRF}_{2}\right)$ was correlated with summed maximum depth for metatarsal and hallux regions

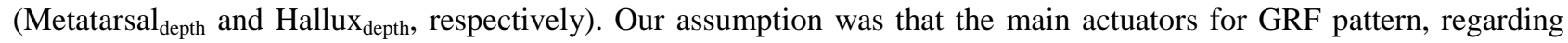
each foot sole region, were respectively: (i) heel for $\mathrm{GRF}_{1}$, and (ii) metatarsals and hallux for $\mathrm{GRF}_{2}$ [12].

\section{Results}

On average, SS speed was $1.36 \mathrm{~m} . \mathrm{s}^{-1}$, speeds above and below SS speed were $1.72 \mathrm{~m} . \mathrm{s}^{-1}$ and $1.04 \mathrm{~m} . \mathrm{s}^{-1}$ respectively. Table 1 shows the outcomes for BH and BM using the stadiometer and force plate, and estimated values obtained by the regression equation proposed by Krishan [14], [15]. In average BM and BH predictions were $\approx 1,0 \%$ and $\approx 1,2 \%$ lower than the experimental value, respectively.

Table 1: Experimental measurements of $\mathrm{BH}$ and $\mathrm{BM}$ and estimated by mathematical equations.

\begin{tabular}{llllll}
\hline & \multicolumn{3}{c}{$\mathrm{BH}(\mathrm{m})$} & \multicolumn{2}{c}{$\mathrm{BM}(\mathrm{kg})$} \\
\cline { 2 - 6 } Subject & $\mathrm{BH}_{\mathrm{FW}}$ & $\mathrm{BH}_{\text {Experimental }}$ & $\mathrm{BM}_{\mathrm{FL}}$ & $\mathrm{BM}_{\mathrm{FW}}$ & $\mathrm{BM}_{\text {Experimental }}$ \\
\hline S1 & 1.70 & 1.74 & 67.27 & 63.94 & 63.90 \\
S2 & 1.78 & 1.90 & 73.01 & 68.23 & 91.83 \\
S3 & 1.70 & 1.74 & 68.98 & 63.94 & 62.87 \\
S4 & 1.68 & 1.63 & 68.37 & 62.80 & 55.78 \\
S5 & 1.77 & 1.81 & 72.64 & 67.37 & 81.32 \\
S6 & 1.68 & 1.63 & 67.52 & 62.80 & 59.03 \\
S7 & 1.76 & 1.76 & 70.20 & 67.09 & 68.03 \\
S8 & 1.66 & 1.67 & 69.35 & 61.94 & 68.39 \\
S9 & 1.68 & 1.77 & 65.35 & 62.51 & 68.92 \\
S10 & 1.68 & 1.65 & 65.08 & 62.57 & 51.98 \\
Mean \pm SD & $1.71 \pm 0.04$ & $1.73 \pm 0.09$ & $68.77 \pm 2.68$ & $64.32 \pm 2.34$ & $67.20 \pm 11.88$ \\
\hline
\end{tabular}

Note: Subject (S), Foot Lengh (FL) and Foot Width (FW). $\mathrm{BH}_{\mathrm{FW}}, \mathrm{BM}_{\mathrm{FL}}$ and $\mathrm{BM}_{\mathrm{FW}}$ estimated by linear regression equations from Krishan $2008 \mathrm{a}$ and 2008 b.

The linear regression equations for Calcaneus depth $_{\text {and }} \mathrm{GRF}_{1}$, and for Metatarsal depth $_{\text {f }}+$ Hallux $_{\text {depth }}$ and $\mathrm{GRF}_{2}$ showed strong $\left(\mathrm{R}^{2}=0.81, \mathrm{p}<0.001\right)$ and medium $\left(\mathrm{R}^{2}=0.56, \mathrm{p}<0.001\right)$ determination coefficients, respectively (Fig. 2). 


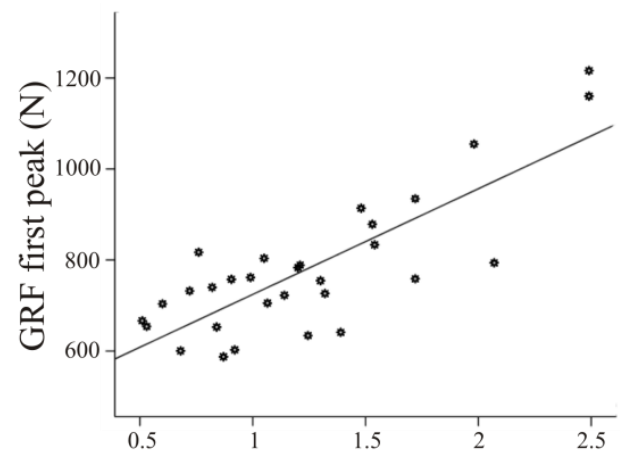

Calcaneus maximum Depth $(\mathrm{cm})$

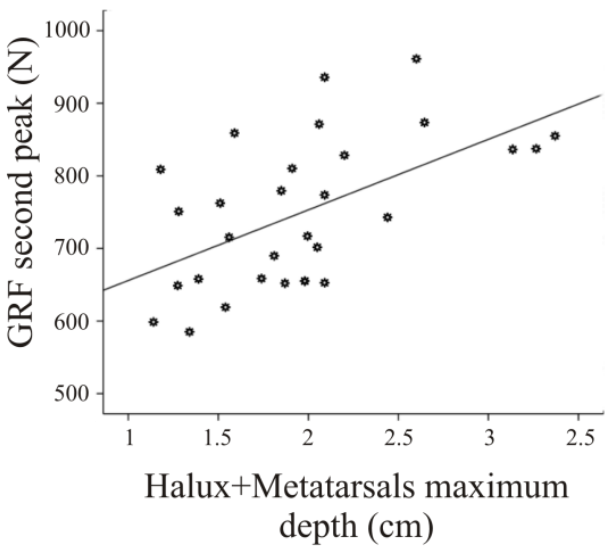

depth $(\mathrm{cm})$

Fig. 2: Relation between calcaneus maximum depth $\left(\right.$ Calcaneus $\left._{\text {depth }}\right)$ and hallux + metatarsal maximum depths $\left(\right.$ Metatarsal $_{\text {depth }}+$ Hallux $\left.\mathrm{x}_{\text {depth }}\right)$ and first ground reaction force peak $\left(\mathrm{GRF}_{1}\right)$ and second ground reaction force peak $\left(\mathrm{GRF}_{2}\right)$.

Calcaneus $_{\text {depth }}$ and Metatarsal ${ }_{\text {depth }}+$ Hallux ${ }_{\text {depth }}$ had significant correlations with $\mathrm{GRF}_{1}$ and $\mathrm{GRF}_{2}$, respectively (Table 2).

Table 2: Pearson correlations and linear regression equations for $\mathrm{GRF}_{1}$ and $\mathrm{GRF}_{2}$ prediction

\begin{tabular}{lll}
\hline GRF peak & Determination coefficient $\left(\mathrm{R}^{2}\right)$ & Linear regression equation \\
\hline $\mathrm{GRF}_{1}$ & $0.81^{*}$ & $\mathrm{GRF}_{1}=232.227$ Calcaneus $_{\mathrm{depth}}+492.227$ \\
$\mathrm{GRF}_{2}$ & $0.56^{*}$ & $\mathrm{GRF}_{2}=97.246\left(\right.$ Hallux $\left._{\text {depth }}+\mathrm{Metatarsal}_{\mathrm{depth}}\right)+558.638$ \\
\hline
\end{tabular}

Note: $\mathrm{GRF}_{1}$ and $\mathrm{GRF}_{2}$ are the first and second GRF peaks in $\mathrm{N}$; Calcaneus depth $_{\text {, Metatarsal }}$ depth $_{\text {and Hallux }}$ apth in $_{\mathrm{cm}} *^{*}$ indicates significant interaction between depth and GRF $(\mathrm{p}<0.001)$.

\section{Discussion}

Human evolution to a bipedal posture resulted in foot changes at structural and functional levels, and these changes are associated with differences on GRFs. Studies showed a GRF pattern for homo sapiens which is different, when compared to primates; while homo sapiens show two distinct GRF peaks during walking, primates have only one [22], [2]. The measurement of GRFs has been an important tool to assess gait, and GRFs are considered as one of the most important external forces acting on the human body. It is due its action that our body is able to initiate or modify body movements. GRFs patterns have been used as a biomechanical parameter in a broad range of studies, including diagnosis, clinics and sports. Each part of these curves has a meaning and a physical interpretation during gait cycle [23]. Thus, the study of GRFs is an important biomechanical tool, and can provide accurate insights for human locomotion studies, inclusive on an evolutional perspective. In the present study, correlation of GRF $\mathrm{G}_{1}$ and $\mathrm{GRF}_{2} \mathrm{with}$ footprint depths indicated a high and moderate determination coefficient, respectively. Thus, it is possible to estimate GRF peaks by means of footprint depths measurements. With this data in hands, anthropologists and biomechanics researchers could work together to a better understanding of pre-historic human locomotion.

In our study, BH and BM experimental data were very similar to predicted values by means of Krishna's equations [14], [15], besides the differences of the study population (South Brazilians versus Northern India Gujjars). The predictions by means of linear regression equations showed similar results to the experimental data $(\approx 1 \%$ sub estimation). This outcome shad a light into the importance of such linear regression equations and the practical applicability of this type of mathematical analysis. It is suggested that the linear regression equations obtained from this study can be applied to future mathematical modeling of human and animal locomotion. It may be useful for a better understanding on animal behavior and human locomotion evolution. With GRF data estimated from the depths of a human footprint, it is possible to build a model for GRF through mathematical approaches (algebraic and/or Fourier series) [24]. Together with other equations, such as $\mathrm{BH}$ and $\mathrm{BM}$ estimation equations, it is possible to obtain numeric data to use as input data for mathematical modeling of locomotion, which could be implemented in the future and be utilized to estimate mechanical work and energy expenditure during walking, for example.

Our study had as a main limitation the lack of a substrate mechanical properties analysis. Raichlen et al. [2] when comparing footprints of subjects walking with knee/hip flexion and a more extended limb position observed that wetter substrates lead to greater toe depths, regardless of gait. In the present study, besides the methodological difficulties on the complex task to quantify substrate proprieties, the similarity of linear regression estimated GRF peaks with experimental GRF data and the significant relation between variables are incontestable outcomes. One alternative is to use GRF peaks differences, i.e. $\mathrm{GRF}_{1}-\mathrm{GRF}_{2}$. Thus, the substrate proprieties differences effect would be minimized and more accurate results could be obtained regardless substrate humidity and composition.

Further studies should use a larger sample size and different walking speeds, our study only analyzed 3 different speeds. Despite the difficulties in data collection and the complexity of substrate composition, this study suggests that there is a 
relation between GRF peak and footprint depth. Therefore, a mathematical model to predict the vertical GRF from footprints would be theoretically possible.

\section{Conclusion}

Regression equations for determination of $\mathrm{GRF}_{1}$ and $\mathrm{GRF}_{2}$ from Calcaneus depth $_{\text {and }}$ Metatarsal depth $_{\text {th }}+\mathrm{Hallux}_{\mathrm{depth}}$ in modern human subjects have been formulated. These equations are of considerable significance for paleontologists and biomechanics researchers as they could work together in order to better understand pre-historic human locomotion. Together with other equations, such as BH and BM estimation equations, it is possible to obtain numeric data to use as input data for mathematical modeling of locomotion, which could be implemented in the future and be utilized to estimate mechanical work and energy expenditure during locomotion.

\section{References}

[1] R.H. Tuttle, the Pitted Pattern of Laetoli Feet, Natural History 99 (1990) 64.

[2] D.A. Raichlen, A.D. Gordon, W.E.H. Harcourt-Smith, A.D. Foster, W.R. Haas Jr., Laetoli footprints preserve earliest direct evidence of human-like bipedal biomechanics, PLoS ONE 5 (2010) 9769.

[3] R.M. Alexander, Modeling approaches in biomechanics, Philos Trans R Soc Lond B Biol Sci 358 (2003)1429-1435.

[4] R.M. Alexander, A model of locomotion on compliant legs, Philos Trans R Soc Lond B Biol Sci 338 (1992) 189-198.

[5] S.F. Vizcaíno, R.A. Fariña, G.V Mazzetta, Ulnar dimensions and fossoriality in armadillos, Acta Theriological Biology 44 (1999) $309-320$.

[6] R.E. Blanco, R. Gambini, R.A. Fariña, Mechanical model for theoretical determination of maximum running speed in mammals, J Theor Biol 222 (2003) 117-125.

[7] R.M. Alexander Estimates of speeds in dinosaurs, Nature 261 (1976) 129-130.

[8] R. Thulborn, Dinosaur Tracks, Chapman Hall, London, 1990.

[9] M. Lockley, K. Chin, K. Houck, M. Matsukawa, R. Kukihara, New interpretations of Ignotornis, the first-reported Mezoic avian footprints: implications for the paleoecology and behavior of an enigmatic Cretaceous bird, Cretaceous Research 30 (2009) 1041-1061.

[10] J. Ackerman, The downside of upright, National Geographic (2006) 126-145.

[11] S. Choudhary, H. Singh, N. Gupta, Estimation of stature from combined length of forearm and hand in Jammu region of India, International Journal of Basic and Applied Sciences, 3 (1) (2014) 8-10.

[12] C. Giacomozzi, V. Macellari, A. Leardini, M.G. Benedetti, Integrated pressure-force-kinematics measuring system for the characterization of plantar foot loading during locomotion, Med Biol Eng Comput 38 (2000) 156-163.

[13] H. Ozden, Y. Balci, C. Demirustu, A. Turgut, M. Ertugrul, Stature and sex estimate using foot and shoe dimensions, Forensic Sci Int 147 (2005) 181-184.

[14] K. Krishan, Establishing correlation of footprints with body weight - Forensic aspects, Forensic Sci Int 179 (2008a) 63-69.

[15] K. Krishan K, Estimation of stature from footprint and foot outline dimensions in Gujjars of North India, Forensic Sci Int 175 (2008b) $93-101$.

[16] L. Margetts, I.M. Smith, J.M. Leng, P.L Mannning, Simulating Dinosaur Track Formation, VII International Conference on Computational Plasticity - COMPLAS (2005), Available online: http://congress.cimne.upc.es/complas05/admin/files/filepaper/p153.pdf.

[17] K. D'août, L. Meert, B. van Gheluwe, D. De Clercq, P. Aerts, Experimentally generated footprints in sand: analysis and consequences for the interpretation of fossil and forensic footprints, Am J Phys Anthropol 141 (2010) 515-525.

[18] G.A. Cavagna, R. Margaria, Mechanics of walking, J Appl Physiol 21 (1966) 271-278.

[19] L.A. Peyré-Tartaruga, Energética e mecânica da caminhada e corrida humana: com especial referência à locomoção em plano inclinado e efeitos da idade, Educação Física - Ciências do Movimento Humano, Faculdade Federal do Rio Grande do Sul, Porto Alegre/RS, Brasil, 136, 2008.

[20] E.F. Manfio, Estudo de parâmetros antropométricos e biomecânicos do pé humano para a fabricação de calçados segundo critérios de conforto, saúde e segurança. Educação Física - Ciências do Movimento Humano, Universidade Federal de Santa Maria, Santa Maria/RS, Brasil, 112, 1995.

[21] D. Atamturk, I. Duyar, Age-related factors in the relationship between foot measurements and living stature and body weight, J Forensic Sci 53 (2008) 1296-1300.

[22] E. Vereecke, K. D'août, L. van Elsacker, D. De Clercq, P. Aerts, Functional analysis of the gibbon foot during terrestrial bipedal walking: plantar pressure distributions and three-dimensional ground reaction forces, Am J Phys Anthropol 128 (2005) 659-669.

[23] V. Racic, A. Pavic, J.M.W. Brownjohn, Experimental identification and analytical modelling of human walking forces: Literature review, J Sound Vib 326 (2009) 1-49.

[24] A. Crowe, M.M. Samson, M.J. Hoitsma, A.A. van Ginkel. The influence of walking speed on parameters of gait symmetry determined from ground reaction forces, Hum Mov Sci 15 (1996) 347-367. 